Canadian Journal of Fisheries and Aquatic Sciences

Canadian

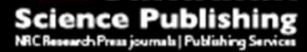

Journal canadien des sciences halieutiques et aquatiques

\title{
Coho salmon escapement and trends in migration timing to a data-poor river: estimates from a Bayesian hierarchical model
}

\begin{tabular}{|r|l|}
\hline Journal: & Canadian Journal of Fisheries and Aquatic Sciences \\
\hline Manuscript ID & cjfas-2014-0554.R2 \\
\hline Manuscript Type: & Article \\
\hline Date Submitted by the Author: & 16 -Jul-2015 \\
\hline Keyword: List of Authors: & $\begin{array}{l}\text { Walsworth, Timothy; University of Washington, School of Aquatic and } \\
\text { Fishery Sciences } \\
\text { Schindler, Daniel; University of Washington, School of Aquatic and Fishery } \\
\text { Sciences }\end{array}$ \\
\hline &
\end{tabular}


Coho salmon escapement and trends in migration timing to a data poor river: estimates from a Bayesian hierarchical model

\author{
Timothy E. Walsworth* \\ School of Aquatic and Fishery Sciences, University of Washington, Seattle, WA 98105, phone: (773)243-9738, \\ fax: (206)685-7471, tewals@uw.edu \\ *corresponding author \\ Daniel E. Schindler
}

School of Aquatic and Fishery Sciences, University of Washington, Seattle,WA 98105, deschind@uw.edu

Keywords: Oncorhynchus kisutch, escapement, hierarchical model, migration timing, Pacific Decadal Oscillation 


\begin{abstract}
Data to inform fisheries management are often limited in remote or low economic-value fisheries. Here, we use a Bayesian hierarchical modeling structure and two alternative migration timing models to estimate the annual escapement of coho salmon (Oncorhynchus kisutch) to the Chignik River (Alaska, USA) in years with little data, borrowing information from data-rich years to inform parameter estimates. Additionally, we examined trends in peak migration timing between 1922 and 2013, and relative to environmental conditions. Our analyses show that annual escapement estimates are prone to substantial errors unless daily escapement is enumerated for at least 7 days after peak migration date. Finally, peak migration date was negatively correlated with the strength of the Pacific Decadal Oscillation in May-August, and increasing over time, though the significance of these associations was dependent on the specific form of the migration timing model used. The modeling approach we present here is easily adaptable to similar situations where data from alternative periods of time or spatial locations can be used to objectively inform local parameter estimates of population characteristics.
\end{abstract}

\title{
Introduction
}

Fishery managers have long recognized the importance of maintaining a sufficient stock of spawning adults to ensure the production of the next generation of individuals (e.g., Russell 1931; Beverton and Holt 1957). Statistical models relating historical spawning stock abundance to future recruitment quantify the productivity of the population at different spawning stock sizes, and allow managers to set biomass or escapement goals. Stock-assessment for many species of commercial or conservation importance relies on indices of abundance derived from a variety of information sources including size structure, age structure, biomass of previous 
harvests, and fishery-independent scientific surveys (Hilborn and Walters 1992). However, these data can be expensive to collect, particularly for fishery-independent data. As such, data are not available for all species, particularly those of little economic value or for stocks in remote locations where monitoring is particularly expensive. As fisheries management agencies are increasingly called upon to shift from single-species to ecosystem-based management (Pikitch et al. 2004), information on the productivity of less economically-valuable species is important for understanding the ecosystem level effects of fisheries. Further, methods to inform management from limited data will need to be increasingly applied to systems and species without long histories of stock assessment.

Due to an anadromous life history and natal stream fidelity of spawning adults, estimating spawning stock abundance for Pacific salmon (Oncorhynchus spp.) is typically conducted by counting the number of adults on the spawning grounds with aerial or ground surveys, or by counting adults migrating up rivers at weirs or counting towers. By counting the number of adults entering spawning grounds, managers can obtain an estimate of spawning abundance and relate future recruitment to it. Management agencies use these relationships to set escapement goals that maximize harvest potential while ensuring sufficient spawning abundance. However, enumerating Pacific salmon escapement is an imperfect process due to incomplete counts (e.g., not counting escapement or spawner abundance every day, biased effort towards more commercially valuable species) and other sources of observation error. Estimates of salmon escapement derived from incomplete counts of spawning or migrating adults use assumptions about arrival timing to estimate total annual escapement (e.g., Hilborn et al. 1999; Su et al. 2001; Parsons and Skalski 2010). Total escapement estimates are particularly difficult 
to obtain in years with few data points and when data are not collected after the peak migration date (Hilborn et al. 1999).

In systems with limited data availability, a Bayesian hierarchical modeling approach provides a means for obtaining reasonable model estimates (Adkison and Su 2001) by sharing information from situations that are data-rich with situations that are data-sparse (Link and Sauer 2002). A hierarchical model structure allows for the use of all available data to inform parameter estimates, simultaneous estimation of all parameters, and assumes that parameter estimates are conditional on related parameters (e.g., Su et al. 2001; Gelman and Hill 2007). Specifically, lower level parameters (e.g., peak migration date in year $i$ ) are drawn from higher level population distributions (e.g., distribution of peak migration times for a river across all years; $\mathrm{Su}$ et al. 2001). Parameters for individual years are treated as random variables drawn from a distribution common to all years. The underlying assumptions allow hierarchical models to objectively borrow information from data-rich years to inform parameter estimates in data-poor years (Adkison and Su 2001; Gelman and Hill 2007).

The number of salmon entering a fishing district or river on any given day during the migration is influenced by two primary factors: the total abundance of salmon returning to the system that year, and the timing of the run (e.g., early or late run). Variation in the timing of the run causes uncertainty for in-season fishery management actions (e.g., opening and closing the fishery), and uncertainty in total escapement estimates made from limited daily escapement counts. A year with larger than average early season escapement can either be experiencing a larger than average spawning population, or could merely be experiencing an early migration in that year. Additionally, salmon migration timing has been demonstrated to be sensitive to environmental conditions such as river discharge, temperature, sea surface temperature (Hodgson 
et al. 2006; Kovach et al. 2013), as well as subject to directional selection from fishery harvest (Quinn et al. 2007). The Pacific Decadal Oscillation (PDO) is a pattern of Pacific Ocean climatic variability that correlates with many marine biological dynamics including salmon productivity (Mantua and Hare 2002; Mantua et al. 1997; Schindler et al. 2005) and migration timing (Kovach et al. 2013). The direction and magnitude of the effect of environmental conditions such as the PDO on spawning migration timing varies among spawning rivers. An understanding of what causes inter-annual variation in salmon migration timing has distinct value for improving fishery management.

The Chignik Lakes watershed on the Alaska Peninsula supports two commercially, culturally and ecologically important stocks of sockeye salmon (O. nerka). While all five species of Pacific salmon are harvested in the fishery, fisheries are focused on sockeye salmon (approximately $70 \%$ of returning sockeye adults are harvested annually; Clark et al. 2006), and interactions among species are not addressed explicitly in current management. Of potential interest is the effect of coho salmon $(O$. kisutch) on sockeye salmon productivity. Juvenile coho salmon have been estimated to annually consume over half of the emerging sockeye fry in Chignik Lake (one of the two sockeye salmon rearing lakes in the system; Ruggerone and Rogers 1992). Therefore, coho salmon exert substantial predation pressure on sockeye salmon populations that may limit their productivity, and thus, the potential for adult recruitment and harvest. For economic and logistic reasons (i.e., low price and late migration timing), there is no directed coho salmon harvest in the system, and coho salmon are only captured incidentally during the sockeye salmon fishery. As there is no directed harvest, coho salmon have no management goals in the Chignik Management Area and little is known about their productivity in the system. 
The single-species approach to managing the sockeye salmon fishery overlooks species interactions with coho salmon populations that may have substantial effects on sockeye salmon productivity. Directed coho salmon harvest at Chignik may benefit the fishery by moving towards a more ecosystem based approach, balancing fishery harvests with ecosystem productivity (Zhou et al. 2010), as well as potentially releasing sockeye salmon from predation constraints (Ruggerone and Rogers 1992). To manage any potential directed coho salmon fishery, managers would ultimately need to understand the productivity of the Chignik Lakes system coho salmon stock. Salmon escapement is enumerated by the Alaska Department of Fish and Game (ADFG) via a weir located at the mouth of the Chignik River and operated seasonally during the sockeye salmon spawning run from the beginning of June through the end of August. Weir removal occurs after most sockeye have migrated into the Chignik River but coincides with the onset of the coho salmon spawning migration, allowing managers to enumerate only a small portion of the coho salmon spawning migration. However, in some years, weir counts continued through the end of September, producing a combination of data-rich and data-poor years of daily migration counts from data spanning two periods: 1922-1936 and 1995-2013.

In this study, we (1) employed a Bayesian hierarchical modeling approach that shares information among data-rich and data-poor years to estimate annual coho salmon escapement to the Chignik Lakes watershed, (2) examined the influence of additional count data from dates beyond the peak escapement date for estimating annual escapement, and (3) examined the relationships between environmental conditions and peak migration timing for coho salmon. The escapement estimates derived from this model could ultimately be used in the management of any future directed coho salmon fishery at Chignik enacted to account for species interactions influencing sockeye salmon dynamics. 


\section{Methods}

Study Site

The Chignik Lakes watershed, on the Alaska Peninsula, consists of two lakes, each supporting populations of sockeye salmon and coho salmon (Fig. 1). Black Lake, a shallow, warm and productive lake in the upper watershed, is fed primarily by the Alec River and drains into Chignik Lake via the Black River. Chignik Lake, a deep, colder, and oligotrophic lake in the lower watershed, is fed by the Black River and Clark River, and drains to Chignik Lagoon and the Gulf of Alaska via the Chignik River.

Daily counts of escapement into the Chignik watershed are made at the Chignik weir by the ADFG near the mouth of the river at the upstream end of tidal influence. Counts are made for the first ten minutes of every hour and extrapolated for the remainder of the hour. Weir counts are widely considered the most accurate method of enumerating Pacific salmon escapement, and are used by managers to make in-season fishery decisions (i.e., opening and closing the fishery). Currently, all anadromous salmonid species are counted at the weir, though historically counts focused on sockeye salmon. Since the mid-1990s, the weir has operated approximately from early June through the end of August, coinciding with sockeye salmon spawning migration timing and the sockeye salmon fishery. Coho salmon spawning runs begin to enter the river around the middle of August and is continuing to build even as the weir is removed. Daily coho escapement data are available from the Chignik Weir from 1922-1932, 1934-1936, and 1995-2013. The weir data from years in the 1920s and 1930s cover the majority of the coho salmon run, extending until the end of September. Data from 1995 until present are limited to the early portion of the run. The methods for enumerating salmon migrating past the 
weir have changed between the two periods, as video cameras were installed in 1994. During all periods, the fish were allowed to pass through 1-3 gates. Fish were counted and identified by technicians standing atop the weir prior to video camera installation (Owen and Price 1995). Historically, gates were closed at night and corrections were made to account for fish that would have passed overnight. Currently, gates are open at night and underwater lights allow technicians to count salmon on video monitors. We assume that any bias derived from these methodological differences is negligible (Quimby and Owen 1994). Additionally, in 2012 and 2013, ADFG operated a DIDSON sonar system $0.25 \mathrm{~km}$ upstream of the weir to enumerate late season escapement of sockeye and coho salmon. These data extend from late August until the end of September. We incorporate the DIDSON data into the observed daily escapement counts for our analyses, for these most recent years. These estimates derive from daily estimates of the total number of migrating salmonids, apportioned into species based on weekly estimates from drift gill net surveys in the upper Chignik Lagoon. The data available to compare weir based escapement estimates to the DIDSON based estimates suggest that DIDSON counts reasonably reflect weir counts, but the limited amount of existing data preclude a comprehensive comparison between these two methods at present. For the purposes of our analysis, we assume that any bias was negligible.

\section{Hierarchical Model Structure and Prior Distributions}

To inform parameter estimates in years with limited escapement data, we used a hierarchical Bayesian modeling framework as described by Adkison and Su (2001). Each model of migration timing used three primary parameters, total escapement $(r)$, peak escapement date $(p)$, and standard deviation of migration timing $(s)$. The hierarchical structure assumes that there 
is an average value for each of these parameters $\left(\mu_{r}, \mu_{p}\right.$, and $\left.\mu_{s}\right)$ in the Chignik River, with among year standard deviation $\left(\sigma_{\mathrm{r}}, \sigma_{\mathrm{p}}\right.$, and $\left.\sigma_{\mathrm{s}}\right)$. Pacific salmon migration timing is generally consistent among years within populations (Burgner 1991; Heard 1991; Sandercock 1991). As such, the assumption of normally distributed peak escapement dates around an among-year mean date is appropriate. By using data from two distinct time periods, we are assuming that the distribution of peak escapement dates, total escapement sizes, and standard deviation of migration timing are consistent between these two time periods. We examined this assumption in further analyses (see Peak Migration Date Trends section). The parameter values in each year $j$ are drawn from the distributions:

$$
\begin{gathered}
p_{j} \sim N\left(\mu_{p}, \sigma_{p}^{2}\right), \\
\ln \left(r_{j}\right) \sim N\left(\mu_{r},{\sigma_{r}}^{2}\right), \\
\ln \left(s_{j}\right) \sim N\left(\mu_{s},{\sigma_{s}}^{2}\right),
\end{gathered}
$$

where $r_{j}$ and $s_{j}$ are obtained after exponentiation after being drawn from a normal distribution on the log scale to ensure positive values. Broad, bounded prior distributions were used for all hyper-parameters because we had little information to otherwise inform them (mean values for the river and among year standard deviation; Table 1; Gelman 2006).

\section{Migration timing models}

We examined the fit of two alternative migration timing models to the daily escapement data, each assuming a unimodal distribution of migration timing. This assumption appears valid from a visual inspection of daily migration counts across years. In the first model, we assumed that daily coho salmon escapement timing was normally distributed $\left(\mathrm{M}_{\mathrm{N}}\right)$ around a peak escapement date: 


$$
\begin{gathered}
E_{i, j}=r_{j} e^{\left(-\frac{\left(d_{i, j}-p_{j}\right)^{2}}{2 \sigma_{j}^{2}}\right)} / \psi_{j}, \\
\psi_{j}=\sum_{i=1}^{n} e^{\left(-\frac{\left(d_{i, j}-p_{j}\right)^{2}}{2 \sigma_{j}^{2}}\right)},
\end{gathered}
$$

where $E_{i, j}$ is coho salmon escapement on day $i$, year $j, d_{i, j}$ is the numeric day $i$ of the year $j, r_{j}$ is the total escapement in year $j, p_{j}$ is the peak escapement date in year $j, \sigma_{j}$ is the standard deviation in arrival timing for year $j$, and $\psi_{j}$ is a normalizing constant which ensures that

$$
\sum_{i=1}^{n}\left(e^{\left(-\frac{\left(d_{i, j}-p_{j}\right)^{2}}{2 \sigma_{j}^{2}}\right)}\right) / \psi_{j}=1
$$

where $n$ is the last day of stream entry (Su et al. 2001). The proportion of the spawning migration passing the weir on a given day is multiplied by the total number of migrating salmon in that year to determine the number of coho salmon passing the weir that day.

As salmon daily escapement counts often demonstrate extended descending limbs, we also examined a model assuming that daily coho salmon migration timing follows a gamma distribution $\left(\mathrm{M}_{\mathrm{G}}\right)$ around a peak escapement date:

$$
\begin{gathered}
E_{i, j}=r_{j}\left(\frac{\left(\beta_{j}^{\alpha}{ }^{\alpha}\right)}{\Gamma\left(\alpha_{j}\right)} d_{i, j}^{\alpha_{j}-1} e^{-\beta_{j} d_{i, j}}\right) / \Psi_{j}, \\
\alpha_{j}=p_{j} \beta_{j}+1, \\
\beta_{j}=\frac{p_{j}+\sqrt{p_{j}^{2}+4 \sigma_{j}^{2}}}{2 \sigma_{j}^{2}}, \\
\psi_{j}=\sum_{i=1}^{n} \frac{\left(\beta_{j}^{\alpha}\right)}{\Gamma\left(\alpha_{j}\right)} d_{i, j}^{\alpha_{j}-1} e^{-\beta_{j} d_{i, j}},
\end{gathered}
$$


where $a_{j}$ is the gamma distribution shape parameter for year $j, \beta_{j}$ is the gamma distribution rate parameter for year $j$, and all other parameters are as in model $\mathrm{M}_{\mathrm{N}}$. The equations for $\alpha_{j}$ and $\beta_{j}$ are derived from the equations for the mode (here, the peak escapement date):

$$
p_{j}=\frac{\alpha_{j}-1}{\beta_{j}}
$$

and the variance (here, the square of the standard deviation of escapement date):

$$
\sigma_{j}^{2}=\frac{\alpha_{j}}{\beta_{j}^{2}}
$$

of the gamma distribution. The gamma model allows for the possibility of asymmetric migration timing around the peak migration date. As in model $\mathrm{M}_{\mathrm{N}}$, the proportion of the spawning migration passing the weir on a given day is multiplied by the total migration size in that year to determine the number of coho salmon passing the weir that day.

\section{Likelihood Structure}

The normal model $\left(\mathrm{M}_{\mathrm{N}}\right)$ and the gamma model $\left(\mathrm{M}_{\mathrm{G}}\right)$ were both fit to the data describing the daily escapement to the Chignik River. Daily salmon escapement counts often demonstrate higher variance during the peak of the run than at the beginning and end of the run. As such, we used a negative binomial error structure to capture over-dispersion in count data (Lindén and Mäntyniemi 2011).

$$
\begin{gathered}
L(\boldsymbol{x} \mid \theta)=\prod_{j} \prod_{i} \frac{\Gamma\left(x_{i, j}+\gamma_{i, j}\right)}{x_{i, j} ! \Gamma\left(\gamma_{i, j}\right)} \rho_{i, j} \gamma_{i, j}\left(1-\rho_{i, j}\right)^{x_{i, j}}, \\
\gamma_{j, i}=\frac{E_{i, j}}{\omega-1+\varphi E_{i, j}}, \\
\rho_{i, j}=\frac{1}{\omega+\varphi E_{i, j}},
\end{gathered}
$$


where $\rho_{i, j}$ and $\gamma_{i, j}$ are the parameters of the negative binomial probability mass function for day $i$, year $j, \varphi$ and $\omega$ are over-dispersion parameters (Lindén and Mäntyniemi 2011), and all other parameters are as above. Models were compared visually and by widely applicable information criterion (WAIC; Watanabe 2010), a fully Bayesian information criteria used to measure predictive accuracy of a model. WAIC uses the posterior predictive distribution to determine predictive ability, not just the posterior mean (as in deviance information criteria DIC, an alternative information criterion for Bayesian analyses), and is valid for use in hierarchical models (Hooten and Hobbs 2015). Model averaged escapement estimates were caluclated from WAIC weights to account for uncertainty in model structure.

\section{Simulated removal of post-peak data}

To examine the influence of daily escapement data after the peak escapement date (i.e. when many enumeration systems are discontinued) on estimates of escapement, we generated data sets in which daily counts were sequentially removed from the end of one year. We then reanalyzed the data with each model (assuming normally distributed $\mathrm{M}_{\mathrm{N}}$ and gamma distributed $\mathrm{M}_{\mathrm{G}}$ migration timing) and compared the annual escapement estimate for the year with data removed to the estimated escapement using the full dataset. The analyses were run with data from 17 days post-peak to 5 days pre-peak remaining in the data set. This analysis was run separately for years 1925, 2012 and 2013, three years for which there was escapement data for at least two weeks after the peak migration date. The percent errors of annual escapement estimates were calculated as:

$$
\% \operatorname{error}_{j}=\left|\frac{E_{t-j}-E_{t}}{E_{t}}\right| \cdot 100
$$


Where $j$ is the number of days of data removed, $t$ is the number of dates with count data available in the data set, $E_{t-j}$ is the predicted annual escapement using the reduced dataset, $E_{t}$ is the predicted annual escapement using the full dataset. The percent error was calculated from ordered MCMC output (i.e., the lowest predicted escapement from dataset $t$ was compared to the lowest predicted escapement from dataset $t-j$ ) to produce a distribution of percent errors.

\section{Trends in Peak Migration Date}

To assess whether coho salmon migration timing has undergone systematic temporal shifts or is correlated with large-scale environmental variation, we compared annual estimates of peak migration date $(\mathrm{N}=33)$ versus year and PDO index values. Long-term environmental datasets that cover the duration of the available coho salmon escapement data are limited, and thus we only examined the PDO index. Monthly average PDO indices were obtained for May through August (available at: jisao.washington.edu/pdo/) averaged to obtain a summer PDO index for each year in our analysis, as these are the the conditions that coho salmon would be experiencing immediately before beginning their upstream migration. We examined the peak escapement dates estimated from our models for trends related to time (i.e., a temporal shift in peak escapement date) and PDO index (e.g., differential escapement timing related to warm or cold PDO years) with linear models. The full model examined was:

$$
p_{j}=\beta_{0}+\beta_{1} Y_{j}+\beta_{2} P D O_{j}+\beta_{3} Y_{j} P D O_{j}
$$

Where $p_{j}$ is the peak escapement date estimate for year $j, Y_{j}$ is the year in year $j$, and $P D O_{j}$ is the summer PDO index in year $j$. The final models were selected by AICc. These analyses were run post hoc for the estimated peak escapement dates from each escapement model separately (i.e., normally distributed migration timing $\mathrm{M}_{\mathrm{N}}$ and gamma distributed migration timing $\mathrm{M}_{\mathrm{G}}$ ). We 
detected no evidence of autocorrelation in residuals from any of the models, except the model relating peak escapement date from $\mathrm{M}_{\mathrm{G}}$ to only the PDO index. This model ultimately had the least support in the data and was not used further. As such, we are comfortable that autocorrelation of model errors did not influence our conclusions.

All hierarchical models were run in JAGS (Plummer 2003) and all additional calculations were carried out in the R Statistical Software Environment (R Development Core Team 2011).

\section{Results}

Escapement Estimates

The model assuming gamma distributed migration timing $\left(\mathrm{M}_{\mathrm{G}}\right)$ had the most support by WAIC (WAIC=-89.99; 74.9\% model weight), compared to the model assuming normally distributed migration timing $\left(\mathrm{M}_{\mathrm{N}} ; \mathrm{WAIC}=-87.81 ; 25.1 \%\right.$ model weight $)$. Both models were effective at capturing trends in daily escapement trends in data-rich years (Figure 2), though, as expected, they produced more imprecise estimates in data-poor years. Estimates of total escapement were more constrained in years with more complete data than in those years with very limited data for all models (Fig. 3). Each model provided similar relative estimates of total escapement between years (i.e., a year with a high escapement estimate for one model generally corresponded with high escapement estimates in the other model), although the model assuming gamma distributed arrival timing tended to produce higher estimates (Fig. 3; Fig. 4c, d). Both models predicted the highest escapement in $1927\left(1.46 \times 10^{5}\right.$ fish for $\mathrm{M}_{\mathrm{N}} ; 1.37 \times 10^{5}$ fish for $\left.\mathrm{M}_{\mathrm{G}}\right)$, and the lowest escapement in $1999\left(1.34 \times 10^{4}\right.$ fish for $\mathrm{M}_{\mathrm{N}} ; 1.84 \times 10^{4}$ fish for $\mathrm{M}_{\mathrm{G}}$; Fig. 4c, d). Annual escapement estimates differed by an order of magnitude among years for both models 
(Fig. 4c, d). Median model averaged escapement estimates varied among years from a low of approximately $1.50 \times 10^{4}$ in 1999 to a high of approximately $1.39 \times 10^{5}$ in 1927 (Fig. 4).

Sensitivity of Escapement Estimates to Post-Peak Count Data

Simulations to test the sensitivity of annual escapement estimates to post-peak data availability demonstrated that errors were greatly reduced when including at least a week of postpeak data for the model assuming normally distributed migration timing $\left(\mathrm{M}_{\mathrm{N}}\right.$; Fig 5). Including one week of post-peak data reduced errors to approximately $10 \%$ (median error) compared to estimates based on the entire run duration. However, as is evident from the analyses from 1925 and 2012 data, episodic escapements present difficulties to model fitting, as the percent error of estimated escapement increased as additional data can capture post-peak pulses of escapement (Fig. 5). The model assuming gamma distributed arrival timing $\left(\mathrm{M}_{\mathrm{G}}\right)$ was much more sensitive to data availability and required nearly two full weeks of post-peak migration data for total escapement estimates to converge on the full-data estimate (Fig 5).

\section{Trends in Peak Escapement Timing}

Linear models relating peak escapement date estimated by the different models generally predicted a negative relationship with the PDO index, and a positive temporal trend in peak escapement date, though the relationships differed among the migration timing models (Table 2). The peak escapement dates estimated from the model assuming normally distributed arrival timing $\left(\mathrm{M}_{\mathrm{N}}\right)$ demonstrate no significant temporal trend in peak escapement date, but a 
significantnegative relationship between peak escapement date and May-August PDO index $\left(R^{2}\right.$ $=0.27, p=0.002$; Table 2; Fig. 6). While the model including additive effects of year and PDO index had the lowest $A I C c(A I C c=167.487)$, the $\triangle A I C c$ between this model and the model including only PDO effects was small $(\triangle A I C c=0.18)$, suggesting that there was no significant difference between the two models fit to the data. Further, a partial F-test of the change in variance explained by the two models suggested that the model including both year and PDO effects explains only a trivial amount of additional variation relative to the model including only PDO effects (partial F-test; $F_{1,30}=3.09, p=0.09$ ). As such, we chose the more parsimonious model including only PDO effects on peak escapement date.

The peak escapement dates estimated from the model assuming a gamma distributed migration timing $\left(\mathrm{M}_{\mathrm{G}}\right)$ demonstrate a positive temporal trend to peak escapement timing (peak escapement date getting later over time), but no effect of PDO $\left(R^{2}=0.61, p<0.001\right.$; Table 2 ; Fig.6). The model including only a year effect had the lowest $A I C c$ value $(A I C c=194.62)$, and had $69 \%$ of the model weight. As such, there is strong evidence that this model has the most support in the data, suggesting later peak escapement dates over time (approximately 1.2 [s.e. = $0.18]$ days later per decade).

\section{Discussion}

As fisheries management agencies face increasing calls to shift towards an ecosystem based approach, more detailed information on all species affected by or affecting the fishery are desired to inform management. There is little economic incentive to manage unexploited species (unless they are of conservation concern), and thus little urgency from management agencies to collect demographic data on these populations. However, information on non-target species may 
be available from monitoring efforts focused on commercially targeted species. This study estimated annual escapement of coho salmon to the river with a Bayesian hierarchical modeling approach, using data on unmanaged coho salmon collected during monitoring of economicallyvaluable sockeye salmon, to inform examination of potential benefits from a more ecosystembased approach to management. Further, we estimated the value of additional data in reducing errors in escapement estimates allowing fisheries managers to weigh the costs and benefits of collecting additional data to monitor and manage coho salmon populations. Finally, we demonstrated that detection of temporal trends and climatic influences on migration timing is sensitive to the underlying model used to estimate migration timing.

Fishery productivity is often characterized by relationships between spawning stock size and production in the next generation. Estimating annual spawning stock abundance is the first step required to characterize the stock-recruit relationship for Chignik River coho salmon. The estimates of annual escapement varied by an order of magnitude among years, and some years were characterized by very low escapements. The presence of a broad range of escapement values is important for characterizing the shape of the relationship between spawning stock and recruitment; if the range of escapements observed were too limited, indications of density dependence may not be apparent in the data (Walters and Martell 2004). Management of any future coho salmon fishery would be improved with the ability to determine sustainable escapement goals for the population.

In data-rich systems, it is possible to obtain constrained estimates of escapement model parameters from single year count data (Flynn et al. 2006). However, in data-poor systems separate estimation of parameters for individual year's results in wide confidence intervals (Hilborn et al. 1999). Hierarchical models provide a framework within which to inform the 
estimates of escapement in data poor systems (Adkison and $\mathrm{Su} 2001$ ). By assuming that there is an average peak escapement date, run duration, and total escapement to the Chignik River, the model borrows information from data-rich years to inform estimates in data poor years. While both models provide qualitatively similar estimates of escapement in any given year relative to other years, the annual escapement estimates can be substantially different between models within a given year, particularly in years with very high or very low escapement relative to the mean. For example, the predicted escapement for 1936 ranged from approximately $6.50 \times 10^{4}$ in model $\mathrm{M}_{\mathrm{N}}$ to approximately $1.22 \times 10^{5}$ in model $\mathrm{M}_{\mathrm{G}}$ (Fig. $\left.4 \mathrm{c}, \mathrm{d}\right)$. This highlights the need to address model assumptions (i.e., uncertainty between normal or gamma distributed migration timing model structures) and use model ensemble averaging that weights the model estimates according to their fits to the data. WAIC provides a method for model averaging Bayesian hierarchical model results (Watanabe 2010), and revealed that the model assuming gamma distributed arrival had the majority of model weight (74.9\% model weight), compared to the model assuming normally distributed arrival timing (25.1\% model weight). This suggests that there is more support in the data for asymmetric than symmetric coho salmon migration timing to the Chignik River. Sensitivity analyses of each of the models to post-peak escapement date data demonstrate the importance of this finding for management purposes.

The ADFG removes the Chignik weir following the closure of the commercial sockeye salmon fishery and the decline in escapement of sockeye salmon in late August or early September. In doing so, the majority of the coho salmon spawning run is not observed. Our analysis demonstrates that continuing daily escapement counts for at least 1 week after the peak escapement date (approximately until September 17 from our estimates of average peak escapement date) allows hierarchical models assuming normally distributed migration timing the 
ability to generate much more accurate estimates of coho salmon escapement. However, models assuming gamma distributed migration timing are more sensitive to data availability and struggle to converge on estimates derived from the full season of data until nearly 2 weeks of post-peak data are available. The flexible shape of gamma distributed migration timing makes the model more sensitive to post-peak variability in daily escapement. The difference in necessary data collection to generate escapement estimates with smaller credible intervals demonstrates the importance of determining whether the coho salmon run follows an asymmetric or symmetric migration timing pattern. With few years with complete escapement data, we rely on information criteria to determine model support in the data. Additional years with complete or near complete escapement data would benefit these estimates, and inform managers of how much longer escapement should be enumerated if coho salmon escapement estimates are desired. Recently, complimentary escapement data collected by hydroacoustics were influential in informing escapement estimates based primarily on weir counts, as the inclusion of late season DIDSON sonar data in 2012 and 2013 resulted in narrow credible intervals around our coho escapement estimates. Continued collection of this data will not only help inform escapement estimates and model assumptions, but also provides a less expensive method of collecting late season escapement estimates in the future if managers decide more effort should be made towards coho salmon management at Chignik.

By using full data sets from the 1920's and 1930's to inform daily escapement estimates in the 1990's through present, our model assumes that the factors influencing migration timing in the first data set are consistent in the second data set. While this assumption may not be strictly met (discussed below), the paucity of post-peak daily escapement counts in the second data set make it difficult to test rigorously. The use of broad priors allows years in the more recent data 
set which have post-peak data to drive peak escapement dates beyond the range detected in the 1920's and 1930's dataset. Our post-hoc analysis of trends in peak escapement timing allows us to examine whether any evidence for these trends exists.

Anthropogenic and natural perturbations have been shown to alter migration timing in many anadromous fish stocks. Understanding how coho salmon migration timing has changed through time and how it responds to environmental conditions would benefit estimation of the spawning run size, particularly if only incomplete escapement counts are available. Bristol Bay sockeye salmon (Quinn et al. 2007) and Columbia River sockeye salmon and American shad (Quinn and Adams 1996) have each been shown to migrate earlier than observed historically, while Columbia River early-run steelhead are migrating later than historically (Robards and Quinn 2002). Sockeye, pink, and coho salmon are migrating earlier to Auke Creek in southeast Alaska (Kovach et al 2013). Changing climate conditions and fishery related harvest pressures have been implicated in these shifts. In systems with escapement goals, managers may exert less harvest pressure in the early part of the fishing season until their escapement goals are met and then open the fishery, thus selecting for earlier migrants in the spawning population. For Chignik River coho salmon, which are harvested incidentally in the sockeye salmon fishery, fishing pressure will be greatest on the earliest migrants and later migrants would be favored in the spawning population. As there is limited overall harvest of coho salmon in Chignik, there could be a weak effect on migration timing, providing a possible explanation for why only the model assuming gamma-distributed migration timing suggests this trend. We detected a negative effect of the PDO on peak escapement timing in Chignik River coho salmon, albeit only in the results of the model with less support from the data $\left(\mathrm{M}_{\mathrm{N}}\right)$. Oceanic conditions may influence the migration timing of Pacific salmon by directly affecting temperature cues or by influencing 
inland precipitation and temperature patterns (Hamlet and Lettenmaier 1999; Keefer et al. 2008; Johnstone and Mantua 2014). Previous research detected no PDO effect on coho salmon migration timing in a southeast Alaskan stream, though a positive association with PDO was detected on sockeye salmon migration timing in the same system (Kovach et al. 2013). Further, environmental conditions associated with PDO are not uniform across the north Pacific, and local hydrology and geomorphology further refine the local expression of these broad climatic conditions experienced by populations of Pacific salmon (Lisi et al. 2013; Leppi et al. 2013). As such, these results highlight the need to consider the effects of environmental conditions in a population-, stock-, or region-specific context. Additionally, recent research has demonstrated instability in the relationship between PDO and North Pacific climatic conditions, suggesting that climate is influenced by the PDO in combination with other indices of atmospheric and oceanic conditions (e.g., Arctic Oscillation, Atlantic multidecadal oscillation; McAfee 2014).

Pacific salmon stocks exhibit many biological traits that are locally adapted to the environmental conditions of their natal streams. As stream temperature is partially controlled by air temperature, rivers in close proximity to each other are likely to have similar run timings (though see Lisi et al. 2013), and rivers at similar latitudes should be more representative of each other than rivers at different latitudes (Hodgson et al. 2006). Previous research has suggested that incorporating information from neighboring streams to inform prior probabilities of run timing into rivers may further constrain estimates in data poor situations ( $\mathrm{Su}$ et al. 2001). If data exist for such systems, they can provide informed prior distributions to escapement estimation in a data poor system, and thus model fits would be less influenced by single data points in small data sets (Hilborn et al. 1999). We examined the potential use of data from other southern Alaskan streams (Little Susitna River, Deshka River, Buskin Creek, Auke Creek) with weir 
counts of coho escapement to inform our estimates of peak escapement date. However, visual examination of the data for these streams demonstrated that the peak escapement dates were either much earlier (Deshka River, Little Susitna River) or later (Auke Creek, Buskin Creek) than was evident in data-rich years in the Chignik River. Coho salmon escapement to the Deshka and Little Susitna Rivers generally peaks at approximately the time when coho salmon begin to enter the Chignik River. Additionally, these rivers are smaller than the Chignik River and escapement may be more controlled by seasonal rain events (Sandercock 1991) or local geomorphic controls on stream thermal regimes (Lisi et al. 2013). The utility of escapement timing data from regional streams is contingent upon the comparability of the size and prevailing environmental conditions of the streams. In the case of Chignik River coho salmon, it does not appear that data from reasonable surrogate rivers exist; thus, our analyses has only used a hierarchical model structure to share data among years, rather than among sites as could be done in other situations.

As fishery managers continue to shift towards a more ecosystem based approach to fisheries management, information on the productivity of non-traditionally targeted (and thus, less well studied) stocks will be needed. As coho salmon present a potential predation bottleneck to the commercially, culturally, and ecologically valuable sockeye salmon of the Chignik Lakes watershed (Ruggerone and Rogers 1992), knowledge of the productivity of the coho salmon stocks is required to understand the interactions between the two species at the level at which the fisheries are managed. Escapement estimates derived from the limited available data by applying Bayesian hierarchical models begin to fill this knowledge gap, allowing researchers to examine relationships between coho salmon escapement and sockeye salmon productivity, and how these interactions may affect the productivity and economics of this fishery. Additionally, 
the results allow for exploration of alternative harvest strategies through simulation modeling, a critical step towards implementing adaptive management strategies to account for species interactions affecting the fishery. In other systems in which there is limited data for the productivity of a historically non-target stock, a hierarchical modeling structure similar to that applied here to the Chignik coho salmon stock can inform management decisions about potential future harvest strategies.

\section{Acknowledgements}

We thank Tim Essington, Ray Hilborn, and two anonymous reviewers for their constructive feedback on previous versions of this manuscript. We thank the Alaska Department of Fish and Game, particularly Adam St. Saviour, Todd Anderson, and Charles Russell for providing the historical weir count and DIDSON escapement data used in this manuscript. We would also like to thank Tim Cline, Tim Essington, Ray Hilborn, Cole Monnahan, Andre Punt, and Jim Thorson for their feedback on model structure and development. This research was funded by a National Science Foundation Coupled Natural-Human Systems grant and the Chignik Regional Aquaculture Association. 


\section{Reference List}

Adkison, M.D., and Su, Z.M. 2001. A comparison of salmon escapement estimates using a hierarchical Bayesian approach versus separate maximum likelihood estimation of each year's return. Canadian Journal of Fisheries and Aquatic Sciences 58(8): 1663-1671.

Beverton, R.J.H., and Holt, S.J. 1957. On the dynamics of exploited fish populations. Fisheries Investigations Series II, Vol.19. Ministry of Agriculture, Fisheries and Food, Her Majesty’s Stationary Office, London, UK, 533p.

Burgner, R.L. 1991. Life history of sockeye salmon (Oncorhynchus nerka). In Pacific salmon life histories. Edited by C. Groot and L. Margolis. University of British Columbia Press, Vancouver. pp. 3-117.

Clark, J.H., McGregor, A., Mecum, R.D., Krasnowski, P., and Carroll, A.M. 2006. The commercial salmon fishery in Alaska. Alaska Fishery Research Bulletin 12(1): 1-146.

Flynn, L., Punt, A.E., and Hilborn, R. 2006. A hierarchical model for salmon run reconstruction and application to the Bristol Bay sockeye salmon (Oncorhynchus nerka) fishery. Canadian Journal of Fisheries and Aquatic Sciences 63(7): 1564-1577.

Gelman, A. 2006. Prior distributions for variance parameters in hierarchical models (comment on article by Browne and Draper). Bayesian Analysis 1(3): 515-534.

Gelman, A., and Hill, J. 2007. Data analysis using regression and multilevel/hierarchical models. Cambridge University Press, New York.

Hamlet, A., and Lettenmaier, D. 1999. Columbia River Streamflow Forecasting Based on ENSO and PDO Climate Signals. Journal of Water Resources Planning and Management 125(6): 333-341. 
Heard, W.R. 1991. Life history of pink salmon (Oncorhynchus gorbuscha). In Pacific salmon life histories. Edited by C. Groot and L. Margolis. University of British Columbia Press, Vancouver. pp. 121-230.

Hilborn, R., Bue, B.G., and Sharr, S. 1999. Estimating spawning escapements from periodic counts: a comparison of methods. Canadian Journal of Fisheries and Aquatic Sciences 56(5): 888-896.

Hilborn, R., and Walters, C.J. 1992. Quantitative Fisheries Stock Assessment: Choice, Dynamics and Uncertainty/Book and Disk. Springer.

Hodgson, S., Quinn, T.P., Hilborn, R., Francis, R.C., and Rogers, D.E. 2006. Marine and freshwater climatic factors affecting interannual variation in the timing of return migration to fresh water of sockeye salmon (Oncorhynchus nerka). Fisheries Oceanography 15(1): 1-24.

Hooten, M.B., and Hobbs, N.T. 2015. A guide to Bayesian model selection for ecologists. Ecological Monographs 85(1): 3-28.

Johnstone, J.A., and Mantua, N.J. 2014. Atmospheric controls on the northeast Pacific temperature variability and change, 1900-2012. Proceedings of the National Academy of Sciences 111: 14360-14365.

Keefer, M.L., Peery, C.A., and Caudill, C.C. 2008. Migration Timing of Columbia River Spring Chinook Salmon: Effects of Temperature, River Discharge, and Ocean Environment. Transactions of the American Fisheries Society 137(4): 1120-1133. 
Kovach, R.P., Joyce, J.E., Echave, J.D., Lindberg, M.S., and Tallmon, D.A. 2013. Earlier Migration Timing, Decreasing Phenotypic Variation, and Biocomplexity in Multiple Salmonid Species. Plos One 8(1).

Leppi, J.C., Rinella, D.J., Wilson, R.R., and Loya, W.M. 2013. Linking climate change projections for an Alaskan watershed to future coho salmon production. Global Change Biology 20: 1808-1820.

Lindén, A., and Mäntyniemi, S. 2011. Using the negative binomial distribution to model overdispersion in ecological count data. Ecology 92(7): 1414-1421.

Link, W.A. and Sauer, J.R. 2002. A Hierarchical Analysis of Population Change with Application to Cerulean Warblers. Ecology 83: 2832-2840.

Lisi, P.J., Schindler, D.E., Bentley, K.T., and Pess, G.R. 2013. Association between geomorphic attributes of watersheds, water temperature, and salmon spawn timing in Alaskan streams. Geomorphology 185: 78-86.

Mantua, N.J., and Hare, S.R. 2002. The Pacific decadal oscillation. Journal of Oceanography 58(1): $35-44$.

Mantua, N.J., Hare, S.R., Zhang, Y., Wallace, J.M., and Francis, R.C. 1997. A Pacific Interdecadal Climate Oscillation with Impacts on Salmon Production. Bulletin of the American Meteorological Society 78(6): 1069-1079.

McAfee, S.A. 2014. Consistency and the Lack Thereof in Pacific Decadal Oscillation Impacts on North American Winter Climate. Journal of Climate 27: 7410-7431.

Owen, D.L., and Price, R.A. 1995. Chignik Management Area, 1995: Commercial Salmon Fishery Management Report to the Alaska Board of Fisheries. Alaska Department of Fish and Game Regional Information Report No. 4K95-45. 
Parsons, A.L., and Skalski, J.R. 2010. Quantitative Assessment of Salmonid Escapement Techniques. Reviews in Fisheries Science 18(4): 301-314.

Pikitch, E.K., Santora, C., Babcock, E.A., Bakun, A., Bonfil, R., Conover, D.O., Dayton, P., Doukakis, P., Fluharty, D., Heneman, B., Houde, E.D., Link, J., Livingston, P.A., Mangel, M., McAllister, M.K., Pope, J., and Sainsbury, K.J. 2004. Ecosystem-based fishery management. Science 305(5682): 346-347.

Plummer, M. 2003. JAGS: A Program for Analysis of Bayesian Graphical Models Using Gibbs Sampling.

Quimby, A., and Owen, D.L. 1994. Chignik Management Area Annual Finfish Management Report 1993. Alaska Department of Fish and Game Regional Information Report No. 4K94-37

Quinn, T.P., and Adams, D.J. 1996. Environmental changes affecting the migratory timing of American shad and sockeye salmon. Ecology: 1151-1162.

Quinn, T.P., Hodgson, S., Flynn, L., Hilborn, R., and Rogers, D.E. 2007. Directional selection by fisheries and the timing of sockeye salmon (Oncorhynchus nerka) migrations. Ecological Applications 17(3): 731-739.

Robards, M.D., and Quinn, T.P. 2002. The migratory timing of adult summer-run steelhead in the Columbia River over six decades of environmental change. Transactions of the American Fisheries Society 131(3): 523-536.

Ruggerone, G.T., and Rogers, D.E. 1992. Predation on sockeye salmon fry by juvenile coho salmon in the Chignik Lakes, Alaska: Implications for salmon management. North American Journal of Fisheries Management 12(1): 87-102. 
Russell, E. 1931. Some theoretical considerations on the "overfishing" problem. Journal du conseil 6 (1): 3-20.

Sandercock, F.K. 1991. Life history of pink salmon (Oncorhynchus gorbuscha). In Pacific salmon life histories. Edited by C. Groot and L. Margolis. University of British Columbia Press, Vancouver. pp. 397-445.

Schindler, D.E., Rogers, D.E., Scheuerell, M.D., and Abrey, C.A. 2005. Effects of changing climate on zooplankton and juvenile sockeye salmon growth in southwestern Alaska. Ecology 86(1): 198-209.

Su, Z., Adkison, M.D., and Van Alen, B.W. 2001. A hierarchical Bayesian model for estimating historical salmon escapement and escapement timing. Canadian Journal of Fisheries and Aquatic Sciences 58(8): 1648-1662.

Walters, C.J., and Martell, S.J. 2004. Fisheries ecology and management. Princeton University Press.

Watanabe, S. 2010. Asymptotic equivalence of Bayes cross validation and widely applicable information criterion in singular learning theory. The Journal of Machine Learning Research 11: 3571-3594.

Zhou, S., Smith, A.D.M., Punt, A.E., Richardson, A.J., Gibbs, M., Fulton, E.A., Pascoe, S., Bulman, C., Bayliss, P., and Sainsbury, K. 2010. Ecosystem-based fisheries management requires a change to the selective fishing philosophy. Proceedings of the National Academy of Sciences 107(21): 9485-9489. 


\section{Tables}

Table 1. Hyper-parameter prior probabilities for Bayesian hierarchical modeling of coho salmon escapement to the Chignik River. The same prior probabilities were used for the hyperparameters in both the model assuming normally distributed migration timing and the model assuming gamma distributed migration timing.

\begin{tabular}{ccc}
\hline Parameter & Mean & SD \\
\hline Peak Migration Day & $\mu_{p} \sim U(231,300)$ & $\sigma_{p} \sim U(0.1,20)$ \\
Annual Escapement & $\mu_{r} \sim U(9,13)$ & $\sigma_{r} \sim U(0.1,3)$ \\
Arrival Time Variation & $\mu_{s} \sim U(0,3)$ & $\sigma_{s} \sim U(0.1,1)$ \\
\hline
\end{tabular}


Table 2. Linear regression results from analysis of peak migration date trends. Values represent associated slopes of predictors. Significance is denoted by asterisks: $* 0.01-0.05, * * 0.001-$ $0.01, * * *<0.001,--$ predictor not significant by least squares regression.

\begin{tabular}{cccc}
\hline Model & Intercept & PDO & Year \\
\hline \hline $\mathrm{M}_{\mathrm{N}}$ & $213.79^{* * *}$ & $-1.46^{*}$ & -- \\
$\mathrm{M}_{\mathrm{G}}$ & 1.67 & -- & $0.13^{* * *}$ \\
\hline
\end{tabular}




\section{$\underline{\text { Figure Captions }}$}

Figure 1. Map of the Chignik Lakes watershed. Inset shows location on Gulf of Alaska side of the Alaska Peninsula. The Chignik Weir is located between Chignik Lagoon and Chignik Lake.

Figure 2. Examples of daily escapement counts (black dots) and model predicted daily escapement counts (grey lines) for data-rich (a, c) and data-poor (b, d) years with models $\mathrm{M}_{\mathrm{N}}(\mathrm{a}$, b) and $\mathrm{M}_{\mathrm{G}}(\mathrm{c}, \mathrm{d})$. Black line represents the predictions using the median parameter estimates, while the thin grey lines represent individual model fits retained in the MCMC chain. Note that y-axes differ among panels.

Figure 3. Posterior probability densities for models $M_{N}(a)$ and $M_{G}(b)$. Shaded region denotes the posterior density of the hyperparameter $\mu_{r}$ and thin lines denote posterior densities for annual escapements $r_{j}$. All distributions are scaled such that all densities are divided by the maximum likelihood value for comparison among models and years.

Figure 4. Model averaged (a,b) and individual model (c,d) annual escapement estimates by year for 1922-1936 (a,c) and 1995 - $2013(\mathrm{~b}, \mathrm{~d})$. Error bars indicate the 80\% credible interval from posterior distributions. Note log scale for y-axis.

Figure 5. Sensitivity of annual escapement estimates to post-peak migration date data. Light grey regions encompass the $95 \%$, medium grey the $80 \%$, and dark grey the $50 \%$ credible intervals for percent error. The dashed line denotes the median estimate of percent error in annual escapement estimates. The dotted line indicates $10 \%$ error. The analysis was run for 
three years with near complete coverage of the migration, and results are presented or each year individually (denoted by year) as well as for all three years combined.

Figure 6. Linear regression results examining the relationship between peak migration date to environmental conditions (May-August PDO index; panels a, b) and year (panels c,d) for models assuming normally distributed migration timing (panels a, c) and gamma distributed migration timing (panels b, d). Solid black lines indicate that the predictor (PDO or year) was a significant predictor of peak escapement date, while dashed lines indicate insignificant relationships. Error bars represent the $95 \%$ credible interval of peak migration date. 


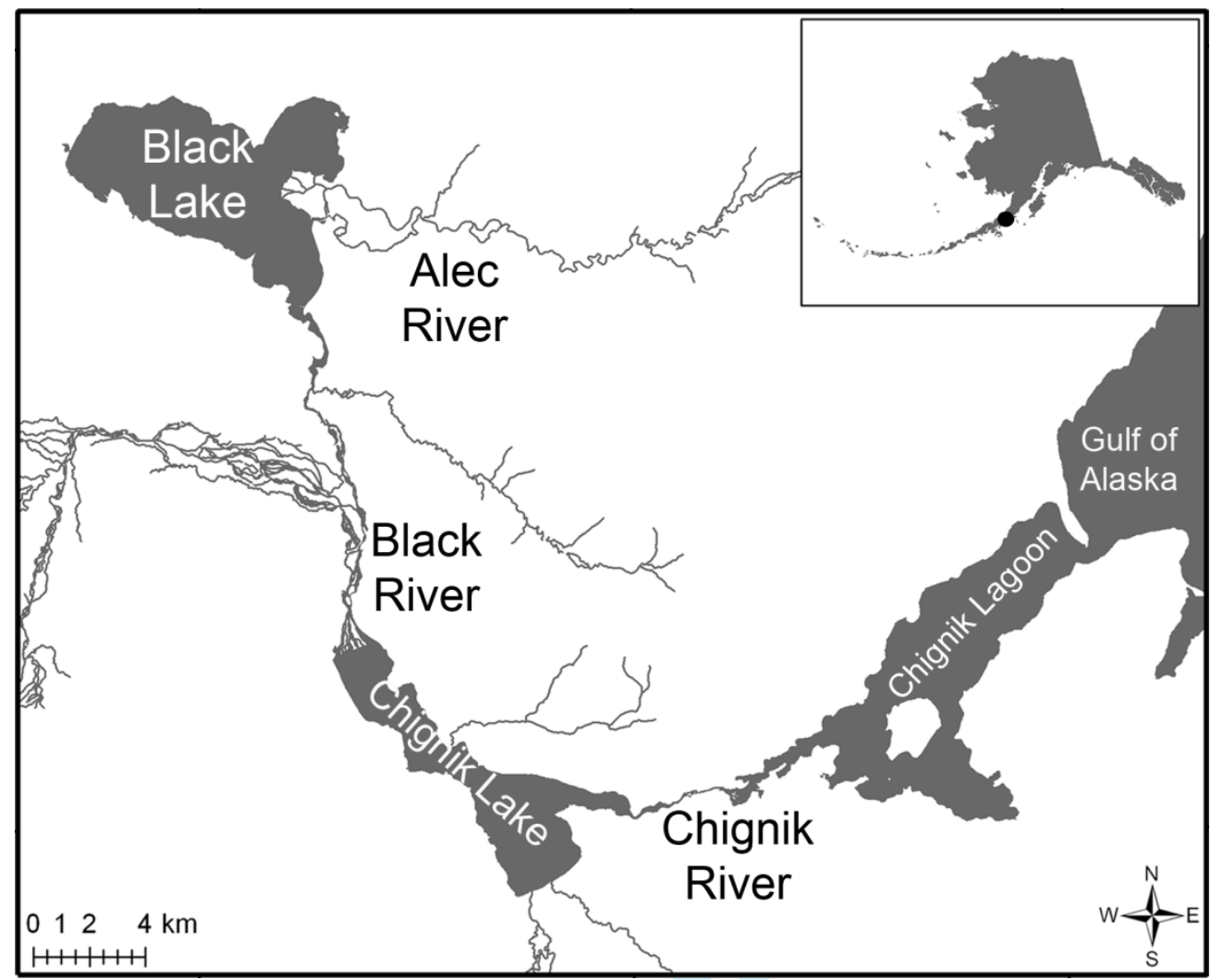

Figure 1. Map of the Chignik Lakes watershed. Inset shows location on Gulf of Alaska side of the Alaska Peninsula. The Chignik Weir is located between Chignik Lagoon and Chignik Lake. 

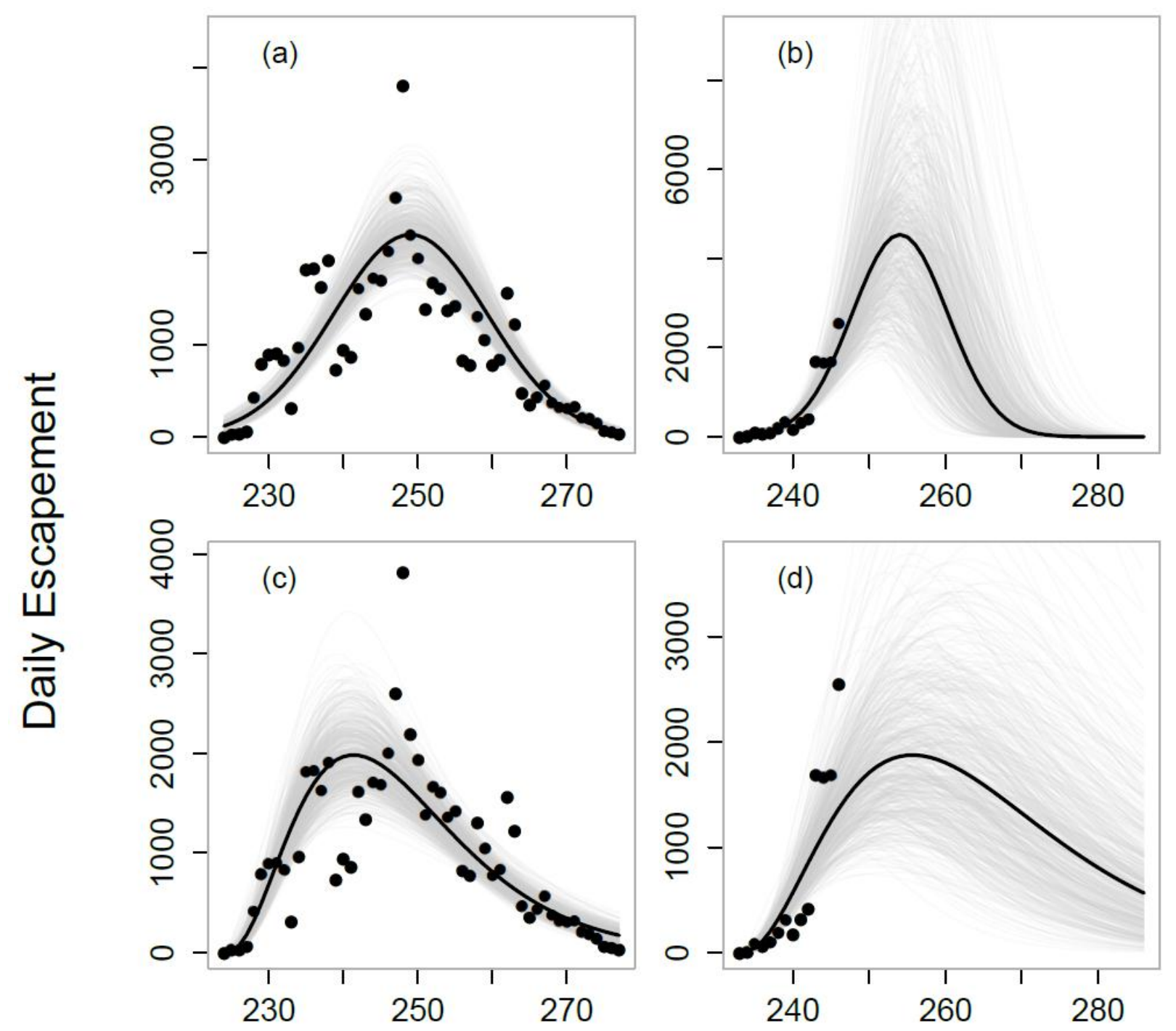

\section{Day of Year}

Figure 2. Examples of daily escapement counts (black dots) and model predicted daily escapement counts (grey lines) for data-rich $(\mathrm{a}, \mathrm{c})$ and data-poor $(\mathrm{b}, \mathrm{d})$ years with models $\mathrm{M}_{\mathrm{N}}(\mathrm{a}$, b) and $\mathrm{M}_{\mathrm{G}}(\mathrm{c}, \mathrm{d})$. Black line represents the predictions using the median parameter estimates, while the thin grey lines represent individual model fits retained in the MCMC chain. Note that y-axes differ among panels. For reference, day 250 is September 7. 


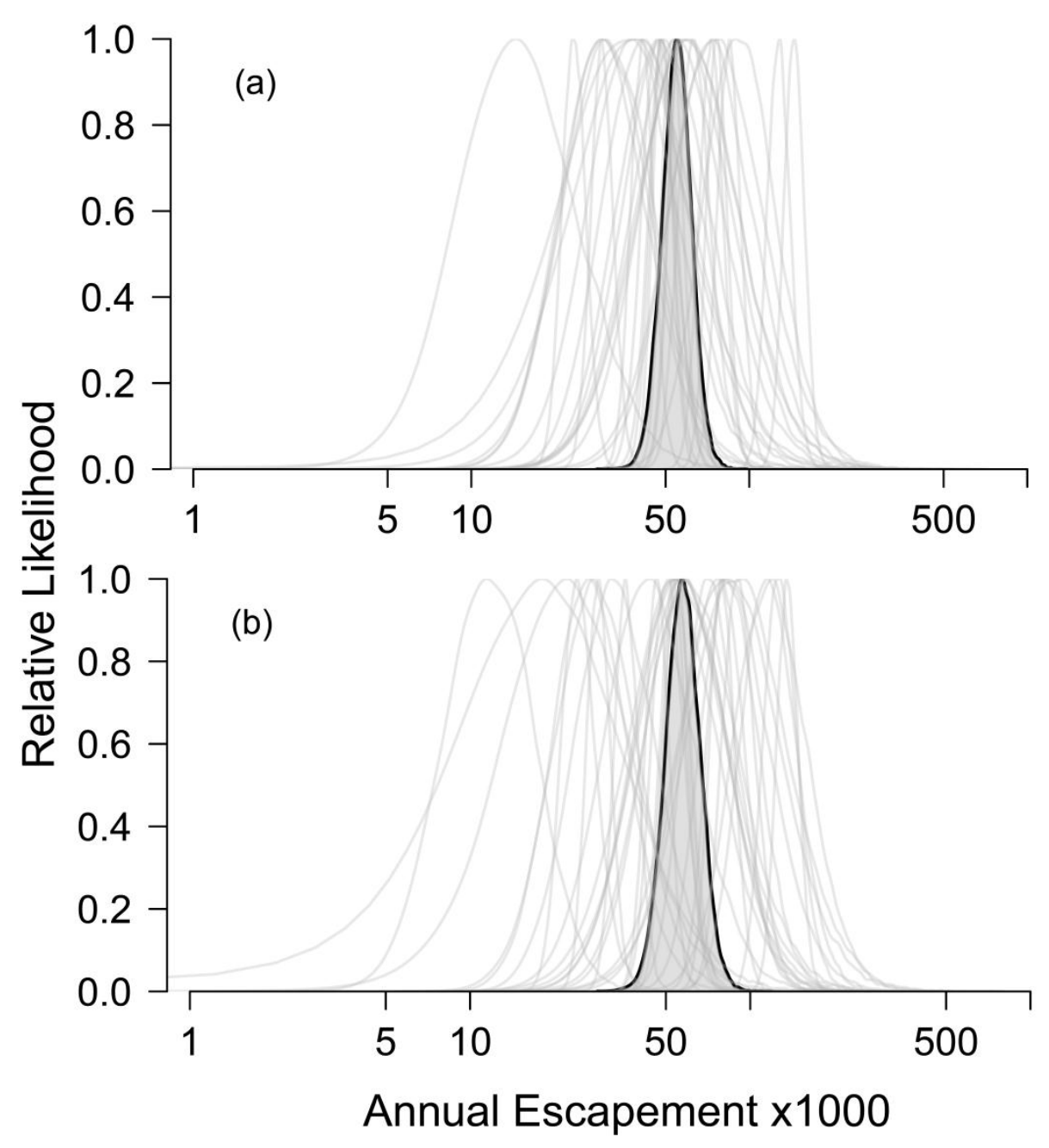

Figure 3. Posterior probability densities for models $M_{N}(a)$ and $M_{G}(b)$. Shaded region denotes the posterior density of the hyperparameter $\mu_{r}$ and thin lines denote posterior densities for annual escapements $r_{j}$. All distributions are scaled such that all densities are divided by the maximum likelihood value for comparison among models and years. 


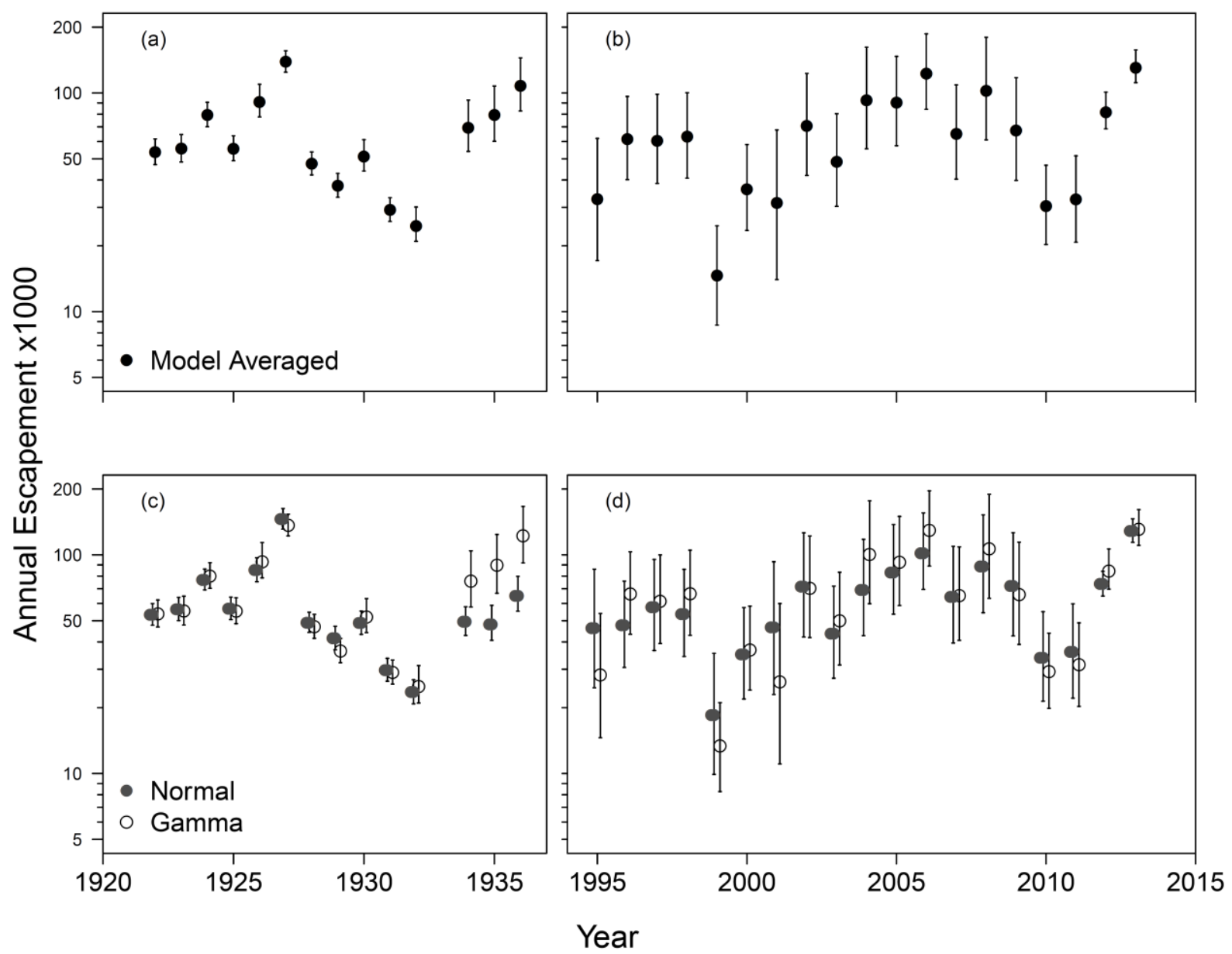

Figure 4. Model averaged (a,b) and individual model (c,d) annual escapement estimates by year for 1922-1936 (a,c) and 1995 - 2013 (b,d). Error bars indicate the 80\% credible interval from posterior distributions. Note log scale for y-axis. 


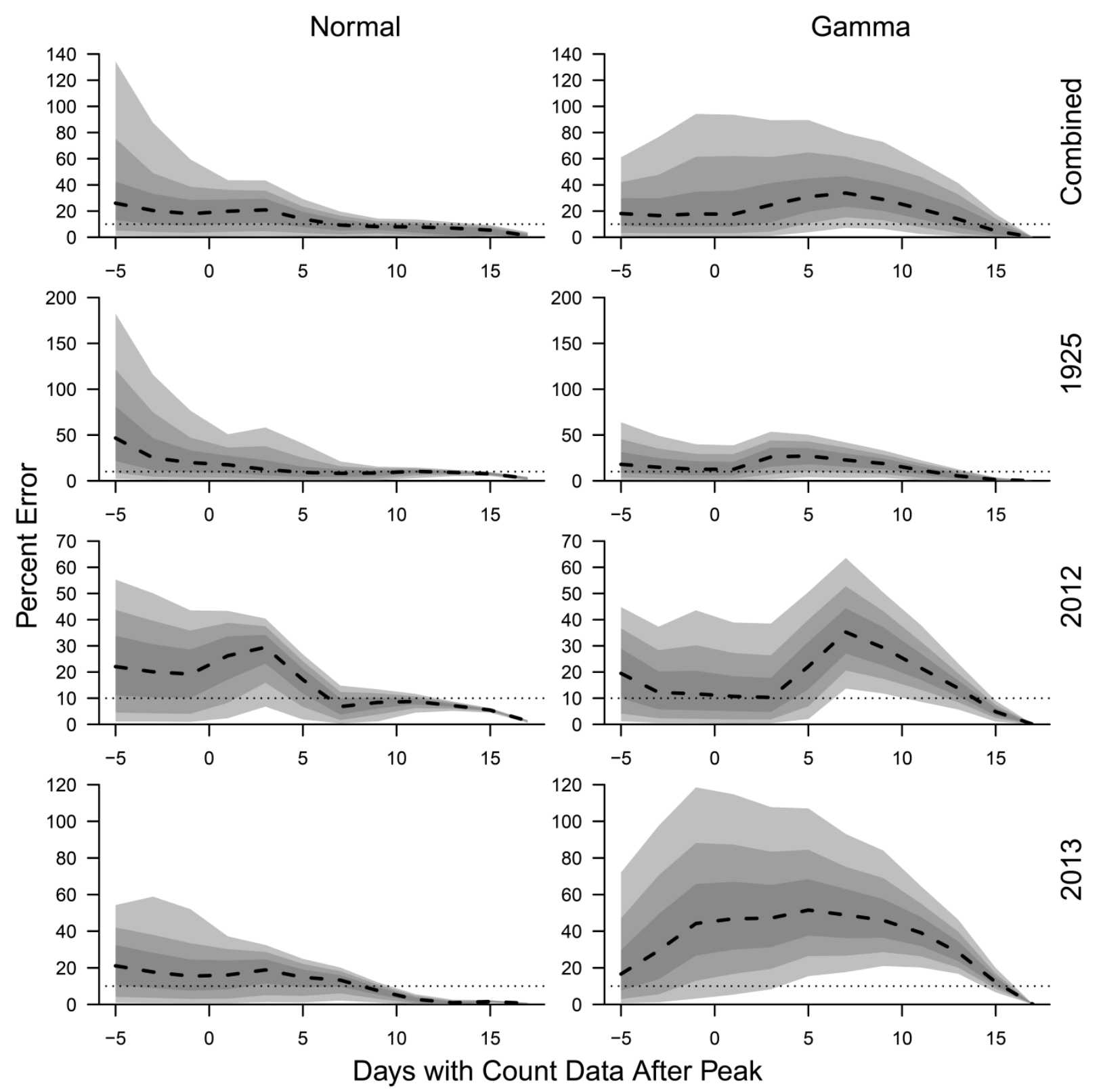

Figure 5. Sensitivity of annual escapement estimates to post-peak migration date data. Light grey regions encompass the $95 \%$, medium grey the $80 \%$, and dark grey the $50 \%$ credible intervals for percent error. The dashed line denotes the median estimate of percent error in annual escapement estimates. The dotted line indicates $10 \%$ error. The analysis was run for three years with near complete coverage of the migration, and results are presented or each year individually (denoted by year on right) as well as for all three years combined. The analysis was run for both models assuming normally (left column) and gamma distributed (right column) migration timing. 

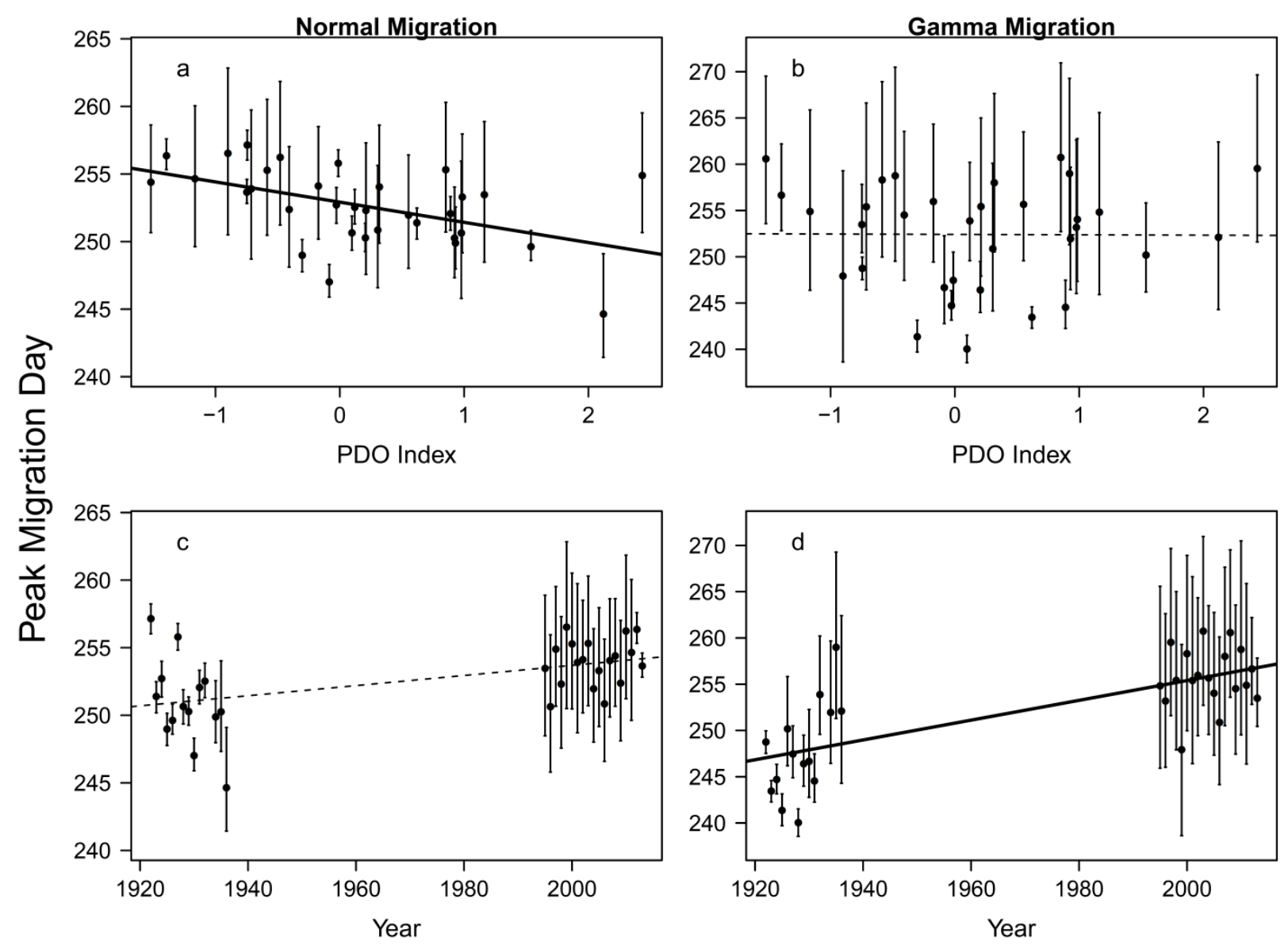

Figure 6. Linear regression results examining the relationship between peak migration date to environmental conditions (May-August PDO index; panels a, b) and year (panels c,d) for models assuming normally distributed migration timing (panels a, c) and gamma distributed migration timing (panels b, d). Solid black lines indicate that the predictor (PDO or year) was a significant predictor of peak escapement date, while dashed lines indicate insignificant relationships. Error bars represent the $95 \%$ credible interval of peak migration date. 